\title{
Prevalence of zoonotic parasitic diseases of domestic animals in different abattoir of Comilla and Brahman Baria region in Bangladesh
}

Md.Hazzaz Bin Kabir ${ }^{1}$, Mohammad Eliyas ${ }^{2}$, Md. Abul Hashem ${ }^{3}$, Mohiuddin ${ }^{4}$ and Omar Faruk Miazi*

${ }^{1}$ Department of Parasitology, Bangladesh Agricultural University, Mymensingh-2202,

${ }^{2}$ Department of Microbiology, Chittagong Veterinary and Animal Sciences University, Khulshi, Chittagong-4202

${ }^{3}$ Department of Pathology and Parasitology, Chittagong Veterinary and Animal Sciences University,

Khulshi, Chittagong-4202

${ }^{4}$ DVM, Chittagong Veterinary and Animal Sciences University, Khulshi, Chittagong-4202

*Corresponding author: Dr. Omar Faruk Miazi, Department of Genetics and Animal Breeding, Chittagong

Veterinary and Animal Sciences University, Khulshi, Chittagong 4202; E-mail: f_cvasu@yahoo.co.in

\begin{abstract}
A study was conducted to investigate about the prevalence of parasitic diseases in different abattoirs in selective area of Bangladesh such as Comilla and Brahmon Baria districts. Animals were examined for post-mortem defects in different abattoirs of those districts. The study started from February, 2008 to August, 2008. The total examined animals were 3510, among them 1460 cattle, 620 buffaloes, 970 goats and 460 sheep. Age, sex and breed of the examined animals were recorded as far as practicable. The overall prevalence of hydatidosis was highest (26.01\%) followed by fascioliasis (20.74\%), amphistomiasis (19.62\%). The prevalence of above mentioned diseases was higher in older animals. The prevalence of hydatidosis, fascioliasis and amphistomiasis was higher in male in case of cattle and goats. But the prevalence of those diseases was distinctly higher in female animals in case of buffaloes and sheep. The proportional prevalence of different disease conditions in cattle was much higher in Hariana breed than those of local and crossbred cattle.
\end{abstract}

Key Words: Abattoirs, zoonotic diseases, parasites, domestic animal.

\section{Introduction}

The main source of animal protein is livestock and their products. Parasitism is one of the main constraints limiting livestock productions. Mortality of animals from parasitic diseases may not be alarming at times but their direct effects in terms of reduced milk, meat, wool, hide production, infertility and loss of stamina of working animals and specially zoonotic impact on human health are considerably greater (Baker \& Muller, 1988). Control of diseases communicable from animals to men under natural conditions is an important task of a Veterinarian. There are so many important zoonotic parasitic diseases such as Hydatidosis, Fascioliasis, Settariosis Trichinellosis, Ascariosis, and Amphistomiasis, etc (Schwabe, 1984). The importance of these diseases as a public health hazard, particularly in rural areas where a close association exists between man and domestic animal is well established. Supervision of the slaughter houses and organization of hygienic precautions concerning food of animal origin are unsatisfactory in Bangladesh. Many slaughter houses and village markets, where animals are slaughtered have no Veterinary supervision and have become the places where dogs congregate and often waste products of animals are kept in the waste heaps from which dogs became infected by hydatidosis. Cattle, buffalo, sheep and goats are the most important livestock of farmers in Bangladesh. They supply meat and milk to meet the partial requirement of protein of high caloric value for the population. The seminar on manpower organized by Food and Agriculture Organization $(F A O, 1965)$ revealed the sufferings of the people of this region due to deficiency of vital food nutrients. But these animals are commonly affected with hydatid cyst, cysticercus and coenurus, causing considerable economic losses in the form of mortality, stunted growth, unthriftiness and partial or complete condemnations of the carcasses at the slaughter houses (Gemmell. 1990). Increasing recognition of the burden of human fascioliasis has occurred; it is now recognised as an emerging zoonosis by the WHO. (Slifco et al., 2000). The zoonosis has a serious impact on both public health \& animal health. The common methods of transmission animal diseases to man include direct contact, through infected fomites or ingestion of infected milk and meat. It is known that, many zoonotic 
diseases like Echinococcosis, Amphistomiasis, Trichinellosis, etc. can be transmitted from animal to human body. Indiscriminate slaughter of food animals sale of meat without ante-mortem and post-mortem examinations by a qualified Veterinarian is not only jeopardize human health but also wide spread environmental pollution. The present study on prevalence of parasitic infections detects in food animal carcasses was undertaken keeping the following objectives in view: to determine the prevalence of zoonotic parasitic disease detects in domestic animal carcasses.

\section{Materials and Methods}

The study covered a period of six months starting from February, 2008 to August, 2008, in Bangladesh. A total of 3510 carcasses of cattle and buffaloes and sheep and goats were examined for postmortem defects in different abattoirs of Comilla and Brahmon Baria region. The examined animals were 1460 cattle, 620 buffaloes, 970 goats and 460 sheep. Age, sex and breed of the examined animals were recorded as far as practicable. The visceral organs were mainly examined and the changes were recorded carefully. The tissues containing lesions were collected, cut into small pieces and preserved in deep freeze for further Parasitological study. After opening the abdominal and thoracic cavities the whole carcass specially was thoroughly checked for the presence of cysts. Any cysts found were collected in normal saline. The number, size, shape and the consistency of cysts were recorded. Incision was given where needed to study the nature of macroscopic lesions. To confirm the diagnosis of parasitic diseases, Helminth parasites found in the visceral organs were collected and examined in fresh stage. The Fasciola sp., Amphistomes sp. and Echinococcus sp. (which cause hydatidosis) were collected in normal saline and washed in distilled water through several changes and kept in glycerinealcohol (70\% ethyl-alcohol 95 parts with pure glycerine 5 parts). Helminth parasites (Fasciola $\mathrm{sp}$ ) in the liver were collected and examined in fresh state. They were shaken vigorously in 1 percent salt solution and then fixed in 10 percent formalin. This was done to prevent contraction of other parasites. Sometimes a fixative consisting of 85 parts of 85 percent ethyl-alcohol, 10 parts of 40 percent formalin and 5 parts of glacial acetic (AFA) was used to fix the parasites.

\section{Results and Discussion}

In order to detect post-mortem defects a total of 3510 carcasses of cattle, buffalo, goat and sheep were examined at different abattoirs of Comilla and Brahmon Baria region. The study revealed that out of 3510 examined animals, the parasitic infections due to one or more disease conditions were found in $1216(83.28 \%)$ of 1460 cattle and $187(30.16 \%)$ of 620 buffaloes, $738(76.08 \%)$ of 970 goats and 189 (41.08\%) of 460 sheep. The overall prevalence of hydatidosis was highest (26.01\%) followed by fascioliasis (20.74\%), amphistomiasis (19.62\%) (Table 1).

Table 1. Prevalence (\%) of parasitic diseases encountered in slaughtered animals

\begin{tabular}{|c|c|c|c|c|c|}
\hline $\begin{array}{c}\text { Disease } \\
\text { Condition }\end{array}$ & $\begin{array}{c}\text { Cattle } \\
\mathrm{n}=1460\end{array}$ & $\begin{array}{c}\text { Buffalo } \\
\mathrm{n}=620\end{array}$ & $\begin{array}{c}\text { Goat } \\
\mathrm{n}=970\end{array}$ & $\begin{array}{c}\text { Sheep } \\
\mathrm{n}=460\end{array}$ & $\begin{array}{c}\text { Total } \\
\mathrm{n}=3510\end{array}$ \\
\hline \multirow{2}{*}{ Hydatidosis } & $29.65 \%$ & $09.19 \%$ & $35.56 \%$ & $16.95 \%$ & $26.01 \%$ \\
& $(433)$ & $(57)$ & $(345)$ & $(78)$ & $(913)$ \\
\hline \multirow{2}{*}{ Fascioliasis } & $27.26 \%$ & $10.00 \%$ & $20.92 \%$ & $14.13 \%$ & $20.74 \%$ \\
& $(398)$ & $(62)$ & $(203)$ & $(65)$ & $(728)$ \\
\hline \multirow{2}{*}{ Amphistomiasis } & $26.36 \%$ & $10.96 \%$ & $19.58 \%$ & $10.00 \%$ & $19.62 \%$ \\
& $(385)$ & $(68)$ & $(190)$ & $(46)$ & $(689)$ \\
\hline
\end{tabular}

$\mathrm{n}=$ Number of animals examined,

( )=Number of infected animals

Out of 3510 slaughtered food animals 913 (26.01\%) carcasses were found to be infected with hydatid cysts in one or more organs. The prevalence of hydatidosis was highest in goats (35.56\%) followed by cattle (29.65\%), sheep (16.95\%) and buffaloes (09.19\%). Among 3510 animal carcasses, 728 (20.74\%) were found to be infected with liver fluke, Fasciola gigantica. Probably fascioliasis was the major cause of reduction of milk and meat production and the maximum cases of cachexia and cirrhosis prevalence of fascioliasis was highest in cattle $(27.26 \%)$ followed by goats (20.92\%) sheep (14.03\%) and buffaloes (10.00\%). Amphistomiasis was the most common parasitic disease as recorded in all animal species. Out of 3510 animals $689(19.62 \%)$ were found to be infected with one or more amphistomes. The indentified amphistome flukes were paramphistomum cervi, Gigantocotyl explanatum and Cotylophoron catylophorum. The prevalence of amphistomiasis was highest in cattle $(26.36 \%)$ followed by goats (19.58\%), buffaloes (10.96\%) and sheep (10.00\%) (Table 1). In another study Shaikh et al. (1983) studied the incidence of parasitic diseases in 
slaughtered animals in Bangladesh. These author identified Fasciola gigantica infection in 59.3\%, $78.7 \%, 27 \%$ and $18 \%$ in cattle, buffaloes, sheep and goats respectively. This study revealed that, the prevalence of Fasciola gigantica infection in carcasses of cattle, buffaloes, goats and sheep were $27.26 \%, 10.00 \%, 20.92 \%$ and $14.13 \%$ respectively (Table 1). Shaikh et al. (1983) recorded much higher rate of Fasciola gigantica infection in cattle and buffalo carcases whereas such rate was higher in this study in cattle and goat carcases. The variation in the rate of prevalence of Fasciola gigantica infection could be due to time, place, season and region of study. On the other hand they observed hydatidosis in cattle, buffalo, sheep and goat carcasses at an infection rate of $14.8 \%, 41.6 \%, 14 \%$ and $0.8 \%$ whereas they recorded Coenurus cerebralis only in buffaloes (0.6\%) and goats (4.1\%). But present result of hydatidosis was detected in $29.65 \%$, $09.19 \%, 35.56 \%$ and $16.95 \%$ cattle, buffaloes, goats and sheep respectively. This result also showed variation especially in case of goats where only $0.8 \%$ carcasses were positive for hydatidosis in Shaikh et al. (1983) report but in this study $35.56 \%$ carcasses were positive for hydatidosis which was much higher than other species of animals. Such variation is also due to the time of investigation, region of study and number of animal's examined. The present study was intended to detect the post-mortem defects particularly zoonotic parasitic diseases in carcasses of food animals in different abattoirs. However, Rahman et al. (1976) performed a slaughter house study in order to diagnose the diseases of goats. They reported the occurrence of parasitic diseases viz. fascioliasis (9 to 17\%), oesophagostomiasis (35 to 65\%), cysticercosis (55 to 70\%) and hydatidosis (12 to 20\%) in examined goat carcasses. This investigation revealed that among the post-mortem defects recorded the prevalence of parasitic diseases was highest in food animals. Such infection comprised of hydatidosis $(26.01 \%)$, fascioliasis $(20.74 \%)$ and amphistomiasis (19.62\%). Species wise prevalence of Amphistomes was 26.36\%, 10.96\%, $19.58 \%$ and $10.00 \%$ in cattle, buffaloes, goats, and sheep respectively.
Table 2. Proportional Prevalence (\%) of parasitic diseases in cattle in relation to Age.

\begin{tabular}{|l|l|l|l|l|}
\hline \multirow{2}{*}{$\begin{array}{c}\text { Parasitic } \\
\text { disease }\end{array}$} & \multicolumn{4}{|c|}{ Age } \\
\cline { 2 - 5 } & $\begin{array}{c}<5 y e a r s \\
\mathrm{n}=525\end{array}$ & prevalence & $\begin{array}{c}>5 \text { 5years } \\
\mathrm{n}=935\end{array}$ & prevalence \\
\hline Hydatidosis & 137 & 26.09 & 296 & 31.65 \\
\hline Fascioliasis & 114 & 21.71 & 284 & 30.37 \\
\hline Amphistomiasis & 96 & 18.28 & 289 & 30.90 \\
\hline
\end{tabular}

Table 3. Proportional Prevalence (\%) of parasitic diseases in cattle in relation to Breed.

\begin{tabular}{|c|c|c|c|c|c|c|}
\hline \multirow[b]{2}{*}{$\begin{array}{c}\text { Parasitic } \\
\text { disease }\end{array}$} & \multicolumn{6}{|c|}{ Breed } \\
\hline & $\begin{array}{c}\text { Hariana } \\
n=478\end{array}$ & $\begin{array}{l}\text { preva } \\
\text { lence }\end{array}$ & $\begin{array}{l}\text { Local } \\
n=603\end{array}$ & $\begin{array}{l}\text { preva- } \\
\text { lence }\end{array}$ & $\begin{array}{l}\text { Cross } \\
n=267\end{array}$ & $\begin{array}{l}\text { preva } \\
\text { lence }\end{array}$ \\
\hline & 213 & 44.56 & 132 & 21.89 & 57 & 21.34 \\
\hline Fascic & 166 & 34.72 & 152 & 25.20 & 46 & 17.22 \\
\hline Amphistomi & 154 & 32.21 & 142 & 23.54 & 57 & 21.34 \\
\hline
\end{tabular}

The prevalence of all diseases was higher in older animals (Table 2). The prevalence was greatly higher in the cattle aged above 5 years (31.65\%) while it was only (26.09\%) in cattle aged below 5 years. In cattle the prevalence of fascioliasis was higher in animals aged above 5 years (30.37\%) than the animals aged below 5 years $(21.71 \%)$ (Table 2). Amphistomiasis was much higher in older (30.90\%) rather than in young cattle (18.28\%). The proportional prevalence of different disease conditions in cattle was much higher in Hariana breed than those of local and cross-bred cattle (Table 3). On the other hand the Hariana breeds of cattle were more susceptible to fascioliasis (34.72\%) than the local $(25.20 \%)$. The rate of infection of amphistomiasis was slightly higher in Hariana breed cattle $(32.21 \%)$ than that of Local cattle (23.54\%) (Table 3).

Shaikh et al. (1983) in their study did not report the prevalence of Amphistome infection in domestic stock of this country. However, number of workers reported the prevalence of Amphistomes in slaughtered meat animals (Kurtpinar \& Lafit, 1970, Yusuf \& Chaudhury, 1970, Kotrla \& Prokopic, 1973, Upadhyay \& Sahai, 1986, Swarup et al., 1987, Patzelt, 1995). Kurtpinar \& Lafti (1970) recorded Amphistomes infection in Iraq in 65 and $40 \%$ of cattle and buffaloes respectively. On the other hand Yousuf \& Chowdhury (1970) observed Gigantocotyl explanatum infection in $57.10 \%$ cases of slaughtered buffaloes in Pakistan. Patzelt (1995) revealed G. explanatum infection in as many as $72 \%$ slaughtered Nili-Ravi buffaloes. 
In cattle the prevalence of hydatidosis, fascioliasis and amphistomiasis was higher in male but higher in female in case of buffaloes and in goats the prevalence of all disease condition was distinctly higher in male animals but higher in female in case of sheep (Table 4).

Table 4. Proportional Prevalence (\%) of parasitic diseases in several species in relation to Sex

\begin{tabular}{|l|c|c|c|c|c|c|c|c|}
\hline \multirow{3}{*}{ Parasitic diseases } & \multicolumn{9}{|c|}{ Species of domestic animal } \\
\cline { 2 - 9 } & \multicolumn{2}{|c|}{ Cattle } & \multicolumn{2}{c|}{ Buffalo } & \multicolumn{2}{c|}{ Goat } & \multicolumn{2}{c|}{ Sheep } \\
\cline { 2 - 9 } & Male & Female & Male & Female & Male & Female & Male & Female \\
& $\mathrm{n}=1080$ & $\mathrm{n}=380$ & $\mathrm{n}=416$ & $\mathrm{n}=204$ & $\mathrm{n}=594$ & $\mathrm{n}=376$ & $\mathrm{n}=344$ & $\mathrm{n}=116$ \\
\hline \multirow{2}{*}{ Hydatidosis } & $31.11 \%$ & $25.52 \%$ & $45.61 \%$ & $54.38 \%$ & $65.21 \%$ & $34.78 \%$ & $44.87 \%$ & $\begin{array}{c}55.12 \% \\
(120)\end{array}$ \\
& $(336)$ & $(97)$ & $(26)$ & $(31)$ & $(225)$ & $(35)$ & $(43)$ \\
\hline \multirow{2}{*}{ Fascioliasis } & $30.37 \%$ & $18.43 \%$ & $43.54 \%$ & $56.45 \%$ & $59.60 \%$ & $40.39 \%$ & $43.07 \%$ & $56.92 \%$ \\
& $(328)$ & $(70)$ & $(27)$ & $(35)$ & $(121)$ & $(82)$ & $(28)$ & $(37)$ \\
\hline \multirow{2}{*}{ Amphistomiasis } & $28.42 \%$ & $20.52 \%$ & $44.11 \%$ & $55.88 \%$ & $62.10 \%$ & $37.89 \%$ & $45.65 \%$ & $54.34 \%$ \\
& $(307)$ & $(78)$ & $(30)$ & $(38)$ & $(118)$ & $(72)$ & $(21)$ & $(25)$ \\
\hline
\end{tabular}

$\mathrm{n}=$ Number of animals examined, $(\mathrm{)})=$ Number of infected animals

Hydatidosis is an important parasitic zoonosis and the disease has been recorded in almost all parts of the world during execution of veterinary inspection in slaughter houses (E1-Badawi et al., 1980, Chermette, 1983, Petkov et al., 1987, Ashraf et al., 1987; Anwar et al., 1993).

Slaughter house survey is a complex way of gathering information on livestock diseases particularly subclinical conditions. However, such surveys must be planned carefully, as animals sold for slaughter may have acquired infection elsewhere in the country. In Bangladesh the district dwellers such as Comilla and BrahmonBaria region their most important item of food chain, meat protein processed through indiscriminate slaughter. The animals brought to slaughter from India through border \& from villages are not examined by a veterinarian for health status whether they are free from diseases or not. Similarly the viscera are not checked after slaughter for any detectable localized and generalized diseases. Meat inspection is necessary to prevent meat borne zoonotic diseases. It is felt that animals to be slaughtered for human consumption must be subjected to Veterinary inspection. Furthermore, there must be slaughter policy and regulation as well as Government Veterinary Officers in every slaughter house of the country.

\section{References}

Anwar, A.H., Hag, A. U. Gill, S.A. \& Chaudhury, A. H. 1993. Prevalence and fertility ratio of hydatid cyst in Slaughtered sheep and goat at Faisalabad. Pakistan Vet. J. 13: 79-81.

Ashraf, M., Khan, M.Z. \& Chishti, M.A. 1987. Incidence and pathology of lungs affected with tuberculosis and hydatidosis in sheep and goats. Pakistan Vet. J. 6: $119-121$.

Chermette, R. 1983. Importance and current position of hydatid disease in France. I.Practical aspects in Veterinary Medicine. Point Veterinaire 14: 15-24.

E1-Badawi. E.K.S.;Eisa, A.M.; S1epenev , N.K. \& Sadd. M.B.A. 1980. Hydatidosis of domestic animals in the central region of Sudan. Bulletin of Anim. Health and prod. Affrica. 27: 249-251.

FAO (Food and Agricultural Organization of the United Nations), 1965. Asian Livestock. Monthly Technical Magazine of the FAO Animal Production and Health Commission for Asia and the Pacific (APHCA) 8: 85-87.

Gemmell, M.A. 1990 Australasian contributions to an understanding of the epidemiology and control of hydatid disease caused by Echinococcus granulosus past, present and future. Int. J. Parasito. 20: 431-456.

Baker, J.R. \& Muller, R. 1988. Journal of Advance in parasitology, Vol 27: pp..244-250

Kotrla, B. \& Prokopic, J. 1973. Paramphistomistomiasis of cattle in Cuba. Acta Veterinaria, Brno. 42:35-44.

Kurtpinar, H. and Lafit, B.M. 1970. Paramphistomiasis of cattle and buffaloes in Iraq. Vet. Rec. . 87: 668. 
Petkov, A., Tsolov, B., Denev, I., Kostov, R., Rusev, I., Zurliski, P., Stoimenov, K., Azpryanov, M. \& Spasov, M. 1987. Distriution of Echinococcus among Animals in Balgaria. Veterinarnomeditsinski Nauki. 24: 51-55.

Petzelt, R. 1995. Epidemiology, Pathogenesis and treatment of Gigantocotyle explanatum infestation among water buffaloes in Panjab, Pakistan. Inaugural Dissertation Fachbereich Vertinarmedizin, Freie Universitat. Berlin, Germany, 1993. 132 p.

Rahman, M.H., Soliman, K.N. \& Shaikh, H. 1976. Healminth parasites encountered in the Abomasum of Ruminants in Bangladesh. Proc. Pakistan Sci. Conf. Univ. of Peshawar pp.17-18.

Schwabe, C.W. 1984. Veterinary Medicine and Human Health, 3rd edn., Williams and Wilkins, Baltimore, pp. $472-85$.
Shaikh, H.U., Haq. M.M., Karim, M.K. \& Khan, M.M.M. 1983. Parasites of Zoonotic importance in domesticated ruminants. Pakistan Vet. J. 3:23-25.

Slifco, T. R., Smith, H. V. \& Rose, J. B. 2000. Emerging parasite zoonoses associated with water and food. Int. J. Parasitol. St. Petersburg, USA.

Swarup, D. Pachauri, S.P. \& Mukherjee, S.C. 1987. Prevalence and clinico-pathology of naturally occuring fascioliasis and biliary amphistomiasis in buffaloes. Indian J. Animal Sci. 57:252-256.

Upadhyay, A.N. \& Sahai, B.N.1986. Studies on Gigantocotyl explanatum; Nasmark: Incidence in cattle and buffaloes and development of miracidium. Indian J. of Anim. Health. 25: 55-59.

Yousuf, I.A. \& Chowdhury, M.A. 1970. Species of paramphistomes from bufaloes in peshawar retion of west Pakistan. Tropical anim. Health and Prod. 2: 235-237. 